\section{EFEITOS DO TURISMO NO DESENVOLVIMENTO REGIONAL}

\section{Luiz ABLAS*}

RESUMO: O artigo trata do problema do desenvolvimento regional em relação à atividade promotora do turismo. Trata-se de um texto teórico onde se procura relacionar uma teoria de desenvolvimento regional às características da atividade do turismo, com vistas a retirar conclusōes sobre a potencialidade desta última em promover o desenvolvimento de uma regiāo.

UNITERMOS: Turismo: desenvolvimento regional; efeitos multiplicadores. Desenvolvimento regional: turismo.

ABSTRACT: The article deals with the regional development problem as related to the tourism activity. It is a theoretical text trying to link the theon of regional derelopment to the characteristics of the tourism activin aiming to draw some conchusions on the potchtialion of in promoting a region s development.

KEY WORDS: Tourism: regional development; multiplving effects. Regional development: tourism.

\section{INTRODUÇÃO}

O problema do descnvolvimento regional tem assumido dimensões importantes em países de grande extensão como é o caso brasileiro, a ponto de empolgar a opiniāo pública de uma forma gencralizada. Na maioria dos casos, a grande questão colocada é a de saber que tipo de atividade produtiva tem condiçōes de germinar em algumas regiōes com condiçōes adversas de produção e mesmo de habitat de vida. Experiências internacionais têm mostrado que existe ampla gama de possibilidades na direção de proposiçōes de atividades que podem ser implantadas em determinadas situaçōes com resultados surpreendentes. Indústrias de localização orientada, como é o caso da aeronáutica

(*) Professor Titular do Depto. de Economia da Faculdade de Economia e Administração da Universidade de São Paulo.

End. para corresp.: FEA A isP - Cidade Universitária - Av. Prot. Luciano Gualberto, 908- CEP 05508 - São Paulo - SP - Brasil. para a região de Toulouse (França), a agricultura irrigada, como tem se observado no Vale do São Francisco (Brasil) e grandes promoções turísticas como o piojeto implantado na região do Languedoc-Roussillon (França), são exemplos significativos que podem ser citados nessa đireção. No que se refere às promoções turísticas e às suas variaçôes, talvez o mais conhecido e também o mais surpreendente refere-se à construção da cidade de Las Vegas (Estados Unidos), experiência única de criação de todo um complexo ligado ao jogo, e que permite o emprego de um volume considerável de pessoas numa regiāo completamente desprovidada de condiçōes para a produçāo, seja agrícola ou industrial. Baseado nesses exemplos marcantes e em outros que poderiam ser buscados na história do desenvolvimento regional, é possívcl levantar uma hipótese de que a arividade murística, de uma forma geral, pode ser considerada como imporsante para a geração de emprego e elevação do nível de renda de uma comunidade habinando uma determinada região.

Considerado dentro dessa problemática, o presente trabalho procura sistematizar um conjunto de idéias relacionadas à potencialidade das atividades ligadas ao turismo como promotoras do processo de desenvolvimento regional. Como o tema é pouco tratado, acreditou-se que a melhor forma de adentrar o assunto seria procurar efetuar um inter-relacionamento entre o processo de desenvolvimento regional apresentado de um forma genérica, com as características da atividade turística, retirando daí as conseqüências consideradas relevantes para o tema tratado.

Com tal preocupação, este artigo foi organizado em três partes, além desta introdução. Na primeira procurou-se sistematizar os aspectos relacionados à questão regional e aos mecanismos de desenvolvimento e da sua transmissão no espaço. Na parte seguinte são esquematizadas as características da atividade turística, destacando aquelas que melhor servem aos objetivos mais gerais do trabalho. Finalmente na última parte é feita uma tentativa de cruzar os dois conjuntos de informaçôes, procurando mostrar até que ponto as atividades ligadas à promoção do turismo podem funcionar, efetivamente, como promotora do desenvolvimento regional. Apenas esta última parte reveste-se de um caráter mais conclusivo, embora assumindo, ainda, uma forma preliminar. Acredita-se que o tema deva ser mais desenvolvido a fim de permitir, no futuro, uma melhor compreensão da problemática. 


\section{QUESTÃO DO DESENVOLVIMENTO REGIONAI}

O desenvolvimento econômico tem sido considerado como uma questão de disponibilidade de bens materiais para a população de um determinado país ou região. Dessa forma, ica privilegiada a produção de bens materiais, sendo que a medida normalmente adotada para aferir o grau de desenvolvimento é o produto ou a renda per capita de um sociedade. Assim considerado, o desenvolvimento envolve um processo de interação entre o Homem e a Natureza que é feito de uma forma cada vez mais intensa, modificando, paulatinamente, as condições de existência dos seres humanos. Atualmente, parece inequívoco que o processo de desenvolvimento deve ser considerado como abrangendo cada vez mais aspectos outros que não a simples relação produção/habitante; deve incluir, por exemplo, as relaçōes sociais, a cultura, o habitat humano, a realização individual e, ainda, o meio ambiente.

Dentro da sua complexidade, o conceito de desenvolvimento pode ser levado a um nível espacial menor que a nação de forma a caracterizar o que poderia ser chamado de desenvolvimento regional. Tal conceito refere-se ao processo descrito sumariamente no parágrafo anterior e levado ao nível de abrangência de uma região. Procurando evitar os aspectos ambíguos do termo, a região, nesse contexto, refere-se, simplesmente, à delimitação geográfica de um território segundo critérios estabelecidos que, geralmente, dizem respeito a algum tipo de polarização. Deve-se considerar, entretanto, que essa delimitação regional, para adquirir maior consistência, deve abranger o âmbito ou área de definição de uma relação social particular. Tal âmbito ou área de definição seria a extensão do território que inclui a localização dos agentes e os mcios diretamente ligados pela relação em causa, bem como as características dos fluxos materiais inerentes à relação, quando for o caso. Adicionalmente, deve-se presumir uma relativa homogeneidade das áreas consideradas, a fim de que seja possível estabelecer um critério de corte que defina a fronteira regional:".

Dada essa frontcira, o conjunto de atividades presentes na região caracteriza a economia regional constituída de um aparelho produtiva e dos meios de consumo presentes na região. Os estudos dessas ativi dades sob o ponto de vista do desenvolvimento têm se constituído no que se convencionou chamar de teorias do desenvolvimento regional.

* Para uma discussão mais aprofundada do assunto veja-se Ablas ${ }^{1}$.
Dentre os enfoques que tratam do assunto, sobressai aquele que

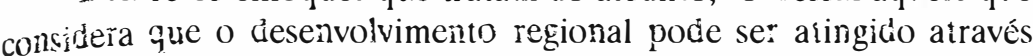
gas forças que permiiem a implantação de um processo de desenvolvimento no interior de uma região dacia. A hipótese de partida é que tal região $s \epsilon$ beneficia de uma vantagem importante que lhe permite basear seu deseñvolvimento sobre as exportaşōes. Como origem desse eníoque teórico tem-se a economia urbana, segundo a qual a base de uma cidacie é constiiuída peias suas exportações, que permitem o pagamerto das suas importaçōes e asseguram o seu crescimento através dos efeitos muitiplicadores sobre a estrutura produtiva interna. Essa teoria, uma vez ampliada para ser aplicada à região, estabelece que a base regionial se compõe de atividades exportadoras, ligadas, geralmente, aos recursos naturais e às conciçōes favoráveis à sua expioração (portos, cìma, quálidade do solo, riqueza do subsolo etc.). Podem ser ativida produtivas - agrícolas ou industriais -, mas podem se constituir, igualrnente, em aigurn tipo de serviço às empresas ou à população. Serviços desse tipo pociem ser ičentificados em algumas regiöes conn características turísticas, por exernplo.

Colocáto sỏ̉ esse eníoq̣ue, o desenvoivimento de uma área qualque repousa sobre a resposta das atividades internas a um crescimento demanda oriuncio do exterior. Esse crescimento é ampliado pela expansão das atividades econômicas locais, através de um mecanismo multipicador, semelhanie ao de investimenios e ai) de comércio exłerior, nos modelos mácroeconômicos nacionais.

Para melhor caracterizar o processo, pode-se imaginar que as ativiades regionais possam ser classificadas em três grupos distintos:

a) ativiỏades exportadoras ou básicas;

b) atividades produtoras de bens e serviços finais para o mercado regional;

c) atividades produtoras de bens intermediários, ligadas as duas primeiras.

As ativiuades exportadoras ou básicas são, em geral, geograficamente cietcrminadas, sendo sua implantação numa região o resultado de uma vantagem comparativa da mesma em relação ao restante da naçấo. No processo de ciesenvolvimento, as atividades possuem a propriedacie de lanças um fluxo líquido de renda dentro da região e će provocar o aumento da produção regional. As características desse tipo de atividacie varia de local para locai, podendo ser industrial. agricola ou ce serviço, incluindo-se, no caso de serviço, a atividade de turismo. 
As atividades produtoras de bens e serviços finais para o mercado regional são atividades que visam satisfazer à demanda final das famílias da região, possuindo, em sua maior parte, área de mercado local ou regional. No processo de desenvolvimento regional, as atividades são amplificadoras dos efeitos oriundos das atividades exportado ras, através do mecanismo de "circuito regional". Tal circuito é formado pela distribuição de rendas dentro da regiảo, em ligação como o aparelho produtor de bens finais para o mercado regional.

Finalmente, as atividades produtoras de bens intermediários para o mercado regional são criadas à medida em que as atividades exportadoras e as produtoras de bens finais geram um mercado suficientemente grande para permitir a implantação de unidades produtivas desse tipo. Os produtos das atividades servem de insumos para as duas primeiras, e a sua implantação é função da demanda de seus produtos dentro do quadro regional. A importância do mercado cieve permitir a uma empresa tornar-se rentável e competitiva com relação ao resto do país.

O conjunto formado por essas três atividades está dividido em duas partes. Uma refere-se às atividacies exportadoras e varia com as mesmas; a outra refere-se às atividades produtoras para o mercado final regional e possui praticamente as mesmas características para qualquer região considerada, se bem que varie com o tamanho dessa última.

Em termos dinâmicos, o processo de crescimento inicia-se com uma elevação autônoma no nível das exportaçōes, que provoca a elevação do nível de produção das atividades exportadoras. Estas provocarão na regiāo dois tipos de efeitos:

a) distribuição de renda aos agentes econòmicos regionais, os quais aumentarão a sua demanda de bens e serviços finais;

b) compras efetuadas pelas atividades exportadoras, promovendo o desenvolvimento das atividades intermediárias da regiāo, com 0 objetivo de se aprovisionar de insumos para aumentar sua produção.

As atividades finais, com a elevação da demanda provocada pelo aumento da renda regional, passarão a níveis superiores de produção. O novo aumento de produção terá também dois tipos de efeitos sobre o sistema produtivo regional:

a) distribui renda adicional que se constitui em novo aumento da demanda final, lançando, por sua vez, um efeito sobre a produção do setor; b) provoca uma elevação nos mesmos moldes daquela produzida pelo crescimento da produção do setor exportador.

Finalmente, as atividades produtoras de bens intermediários receberão os efeitos do aumento das compras dos dois outros grupos de atividades e passarão a um níveỉ mais elevado de produção. Tal passagem provocará uma distribuição de renda sob forma de remuneração aos fatores. Essa nova distrubuição de renda ìnduzirá, por sua vez., um crescimento das atividades finais. No próprio interior das atividades intermediárias, existe um efeito de auto-alimentação que é traduzido pelas compras de bens intermediários para a produção de outros bens intermediários.

Pode-se, assim, tentar sistematizar os diversos efeitos perceptíveis no funcionamento do sistema de produção regional, os quais podem ser considerado a partir de duas óticas. De um lado existe uma espécie de indução que se materializa por um fluxo de compras de bens entre âs empresas componentes da economia regional; são essencialmente as compras efetuadas pelas atividades exportadoras, pelas atividades finais e pelas próprias arividades intermediárias ao setor produtor de bens intermediários. De outro lado existe um fluxo de rendas que provoca o desenvolvimento das atividades produtoras de bens finais para o mercado local e regional; são os valores adicionados nos três grupos de atividades que aparecem sob a forma de remuneração aos fatores de produção.

Cada um desses dois fluxos difunde-se num meio diferente. $\mathrm{O}$ primeiro é formado pelas ligaçōes intersetoriais e a importância de seu efeito será função da riqueza do conjunto dessas ligaçōes. O segundo é constituído pela estrutura de consumo das famílias na regiāo, em ligação com a distribuição de renda na mesma (circuito regional).

Esses dois meios de difusão têm suas características próprias, e o seu dinamismo em assimilar e multiplicar os efeitos provenientes do aumento da demanda exterior irá determinar as possibilidades de desenvolvimento econômico da região considerada.

\section{CARACTERÍSTICAS dA ATIVIDADE TURÍSTICA}

O turismo pode ser definido como a atividade de transportar visitantes, acomodá-los e colocar à sua disposição meios de lazer e recreação nos sentido amplo?2 
Um dos principais aspectus da atividade turística é a possibilida. de da existência de atraçōes que possam incentivar o deslocamento de pessoas através de viagens. Embora exista controvérsia sobre o assun. to, é comumente aceito que as viagens a negócios também possuem um componente turístico, na medida em que utilizam as mesmas insta. lações e meios de transporte que as efetuadas em busca de lazer. $\mathrm{Na}$ verdade, a amplitude do que se pode considerar como motivação para viagens é mais ampla do que a atração turística tradicional, incluindo aspectos relacionados a descanso, esportes, recreação, tratamento de saúde, aspectos culturais (música, arte, folclore, religião etc.), desejo de conhecer novas pessoas e povos, negócios, visita a parentes e amigos, fuga da rotina etc. Ainda, aspectos mais relacionados à própria realização pessoal podem motivar viagens, estudos, participação em convenções, busca de "hobbies" e, até, o desejo de se diferenciar das demais pessoas.

Do ponto de vista econômico, o turismo pode ser visto como a atividade que permite às pessoas derivar de uma viagem algum tipo de benefício psíquico que eleva a sua satisfação. Pode-se, assim, indentificar todo um conjunto de atividades que se dedicam à oferta de serviços, tornando possíveis tais viagens e, conseqüentemente, tais benefícios.

Genericamente, identificam-se três objetivos para a atividade turística como prestadora de serviços. Em primeiro lugar encontra-se a satisfação dos benefícios de ordem psíquica a serem auferidos pelos próprios turistas. A seguir vem a viabilidade econômica das atividades prestadoras de serviços e ofertantes de bens para os turistas. Finalmente, deve-se chamar a atenção para os impactos, em termos de emprego e nível de renda, para a comunidade ou região onde ocorrem as atividades turísticas. Na maior parte do tempo, esses objetivos são compatíveis mutuamente, acreditando-se que maximizar a experiência pessoal do turista cria condições para a continuidade do fluxo turístico e para o aumento dos gastos no local, elevando a rentabilidade dos negócios ligados ao setor e maximizando os efeitos sobre as populações locais.

Do ponto de vista dos aspectos econômicos, é possível visualizar o conjunto das atividades turísticas sob um prisma teórico, de tal forma a verificar o scu papel sob os três pontos de vista apresentados no item 2 e, principalmente, sob a ótica do desenvolvimento regional que é o uhjeto deste texto.

Inicialmente, deve-se considerar o "efeito motor" de qualquer atividade turística representado pelas atraçōes turísticas de uma form? geral. Esse aspecto é crucial para a satisfação do turista e o sucesso da atividade. No entanto, a sua distribuição geográfica causa uma extrema diferenciação entre as diversas localidades passíveis de serem desenvolvidas em termos turísticos. Deduz-se, então, que a identificação dessas atraçōes é o ponto de partida para o planejamento local com base nesse tipo de atividade.

Dadas essas considerações, todo o conjunto de atividades voltadas para $\mathrm{O}$ atendimento do turista está ligado às potencialidades das atrações. Na realidade não existe uma demanda isolada de quuartós de hotel, por exemplo, sem a presença simultânea das transportadioras, dos restaurantes, das lojas de lembranças etc. Quando um turista resolve destinar uma certa importância de seu orçamento para uma viagem turística, estará elevando a demanda de um conjunto de bens e serviços que são ofertados pelo conjunto das atividades turísticas. O dono de um hotel não poderá vender os serviços de um quarto, a menos que o turista tenha efetuado a viagem até o loca! do hotel. O restaurante não terá o seu cliente se não houver hósp̣edes no hotel, e assim por diante. Isso mostra que cada um dos componentes do serviço é parte de um "produto" mais amplo que será o serviço de turismo. Nesse sentido, a diversidade dos serviços prestados tornam os membros da atividade turística individualizados, ao mesmo tempo em que a sua interdependência é crucial. Isso dá uma característica coletiva à arividade, fazendo com que seus componentes acabem "raciocinando" de acordo com uma vontade geral.

Além disso, a atividade tem limitações tanto do ponto de vista da renda disponível pelos turistas como do tempo disponível para a viagem e o lazer. A elasticidade renda da demanda de turismo, de uma forma geral, é um componente importante nas consideraçōes sobre a viabilidade do setor em uma dada região.

Todas essas características, em princípio, mostram que o lurismo tem uma potencialidade na promoção do desenvolvimento de uma região, como discute-se a seguir.

\section{TURISMO E DESENVOLVIMENTO REGIONAL - CONCLUSÕES PRELIMINARES}

Nos itens 2 e 3 esquematizaram-se algumas idéias sobre o processo de desenvolvimento regional e as peculiaridades da atividade turística, de forma relativamente autônoma. Neste item aborda-se o seu inter-relacionamento, razāo porque apresentam-se caracicrísticas mais conclusivas que as anteriores. 
A argumentação efetuada a propósito das caracteristicas do de. senvolvimento regional pode ser adaptada para verificar a efctividace da arvidade unísica como motora desse orocesso. Como ia visto, exis. em dois aspectos relevantes: c caráter da atividade exportadora exó. gena e o meio de difusáo dentro da própria economia regional.

No due se refere ao primeiro asnecto - carbler la atividade ex- ortadora exogena - é interessante verificar oue as características da atividade turística permiem que da assuma, en algumas situaçōes, um papel de ativiade motora para a região. Pela sua próntia cssência, tal atividade significa uma exportaçōo da regin̆o para o restante do país, havenfo, em contranartida. un fiuxo de pagamentos oriundo de ou. tras regiōies. Em situaçöes de baixos níveis de desenvolvimento para algumas regiües, como ocorre no caso brasileiro, não deve ser descartado o potencial para atrair investimenios e propiciar a criação de empregos. Como foi visto anteriormente, as possibilidades de aparecimento de atraçōes turísticas săo, praticamente, inesgotáveis, dependendo, em grande parte, da criatividade dos planejadores e das comunidades locais: a natureza está presente em todas as partes; eventos históricos deixam os seus traços nos locais onde ocorreram; a cultura local, por si só, já significa um atrativo para visitantes de outras regiões; a arte popular desenvolve-se espontaneamente em muitos locais; até uma ação planejada, como criar uma cidade destinada à recreação (Las Vegas, por exemplo), pode significar o aparecimento de uma atração turística. Parece, portanto, inquestionável que o turismo possa assumir papel importante na geraçāo dos efeitos iniciais para o desenvolvimento regional.

Uma vez descoberta, implantada ou desenvolvida, a atração turística, funcionando como atividade motora, ixá projetar sobre a região uma série de efeitos que terão por base a complementariedade com as atividades locais, constituindo-se essas últimas no meio de difusão - o segundo aspecto relevante. Esse meio será formado, basicamente, pelas relações de compra e venda entre os agentes presentes na região e no retorno da distribuição de renda sobre as estruturas de consumo. Tais aspectos têm sido considerados, englobadamente, sob a análise dos multiplicadores regionais.

Os multiplicadores regionais, embora possam ser derivados daqueles calculados para o nível nacional, não podem ser substituídos sumariamente por estes últimos, que em geral são mais elevados, principalmente pelo volume considerável de fugas presentes no caso regional. Economias regionais com estruturas produtivas mais amplas permitem a geração de um maior volume de efeitos multiplicadores locais. Adicionalmente, hens e serviços produzidos règionalmente com salários elevados e com conteúdos de lucros significativos, e que so destinam a vendas aos turistas, contribuem de forma mais importante para a economia regional do que aqueles com elevado grau de fugas, como, por exemplo, as casas alugadas para temporada mas de apropriedade de não-residentes.

Geralmente os estudos de multiplicadores de turismo levam em conta um conjunto de fatores que devem ser considerados separadamente ${ }^{2}$, e que sc referem a:

a) gastos efetuados por hóspedes em hotéis;

b) gas?os efetuados em aluguel de casas;

c) gastos com aluguel de quartos em casas de família;

d) despesas efetuadas com o aluguel de espaços para camping;

e) despesas com compras nas lojas da região;

f) gasios de investimentos (basicamente construção de imóveis);

g) pagamento de alguns tipos de taxas incidentes sobre os gastos na região (imposto sobre o consumo, por exemplo).

Os valores obtidos para esses tipos de multiplicadores, para o caso de itha de Anglesey (Inglaterra), foram da seguinte magnitude:.

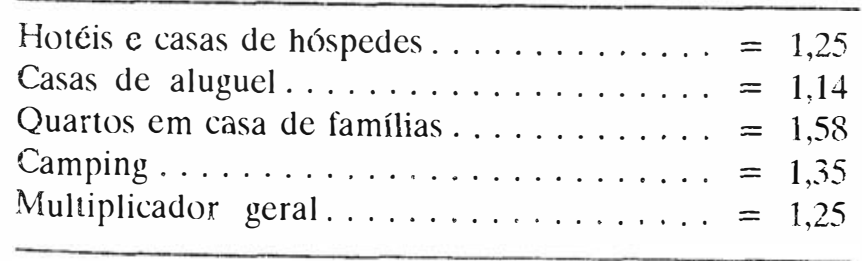

Os resultados acima podem ser tomados como exemplo da importância dos efeitos multiplicadores das atividades turísticas, devendo-se considerar, ainda, que os mesmos se referem a uma ilha que, além de possuir uma pequena dimensão, tem grande parte dos seus serviços supridos a partir do continente. Para economias regionais mais amplas e mais integradias, os resultados para os multiplicadores serão, certamente, mais significativos. Aliás, a dimensão do território analisado deve ser considerada com cuidado, pois envolve a idćia de escala mínimá para compatibilizar os diversos aspectos da atividade. dssim, preconiza-se uma espécie de desenvolvimento equilibrado, onmentingimento de determinados níveis de atividade $\mathrm{cm}$ alguns segmentos do complexo turístico dependerão da atividade dos demais. Como sabe, linhas aéreas, hotéis, restaurantes, salōes de danças e 
casas de diversões possuem um tamanho mínimo para funcionar e um tamanho ótimo para maximizar os seus resultados. Espera-se, assim, um equilíbrio entre os diversos componentes do setor para que seja possível o seu desenvolvimento global.

Há indicaçōes, portanto, de que a atividade turística possui um claro potencial para a promoção do desenvolvimento regional, principalmente ao se considerar que os efeitos positivos sobre a estrutura produtiva regional ocorrem a prazo mais longo, através da criação de um ambiente propício à implantação de outros tipos de atividades.

\section{BIBLIOGRAFIA}

1. ABLAS, L.A.Q. Intercâmbio desigzal c subdescnvolvimento regional no Brasil. São Paulo, FIPE/Pioneira, 1985. (Série Estudos Econômicos).

2. McINTOSCH, Robert W. Tourism, principles, practices, philosophics. Columbus, Grid Inc.. 1972.

3. ARCHER. B. H. e Christine B. Owen. Toward a Tourist Regional Multiplier. Regional Studies, Pergamon Press, vol. 5, p. 289-294, 1971. 